\title{
Estudo da qualidade do ar e a atividade siderúrgica na cidade de Volta Redonda
}

\author{
Air quality study and the steel activity in Volta Redonda city
}

\author{
1 Náthaly Lacerda Tonon e Rocha nathaly.tonon@hotmail.com \\ 2 Claudinei de Souza Guimarães \\ 1 Discente do Programa de Mestrado de Engenharia Ambiental da Universidade Federal do Rio de Janeiro. \\ 2 Professor da Escola de Química da Universidade Federal do Rio de Janeiro.
}

\section{Resumo}

Apesar das medidas de prevenção e controle da poluição atmosférica, as indústrias siderúrgicas são percebidas pela população ao seu redor como uma das maiores fontes de emissão de poluentes, principalmente, em relação à qualidade do ar. Nesse sentido, as emissões atmosféricas devem ser consideradas como aspectos relevantes para a gestão ambiental e serem tratadas com restrição às empresas. 0 objetivo do estudo em questão foi realizar uma análise da qualidade do ar da cidade de Volta Redonda, considerando dados disponíveis, entre os anos de 2010 a 2014, em um comparativo com as legislações brasileira, europeia e norte-americana, bem como sua possível correlação com as atividades de uma indústria siderúrgica localizada no centro da cidade. Os resultados demonstraram que, em algumas localidades e nos períodos avaliados, os níveis de qualidade do ar na cidade ultrapassaram os limites da legislação para os parâmetros Partículas Totais em Suspensão (PTS), Material Particulado Inalável $\left(\mathrm{MP}_{10}\right)$ e Ozônio $\left(\mathrm{O}_{3}\right)$, considerando que a atividade siderúrgica possivelmente contribui para esse cenário. Em um comparativo entre as legislações, constatou-se ainda que a legislação brasileira é menos restritiva que as demais, carecendo, portanto, de atualização.

\section{Palavras-chave}

Qualidade do ar, Volta Redonda, Indústria Siderúrgica.

\begin{abstract}
Despite the prevention measures and air pollution control, the steel industry is perceived by the population around it as one of the major sources of pollutants emission, mainly in relation to air quality. In this sense, atmospheric emissions should be considered as relevant aspects to environmental management and be treated with restraint. The purpose of the study was to perform an analysis of Volta Redonda city air quality, considering available data between the years 2010 to 2014, in a comparison with the Brazilian, European and North American legislation, as well as its possible correlation with the activities of a steel industry located in the center of the city. The results showed that, in some localities and periods evaluated, the air quality levels in the city exceeded the limits of the legislation for the parameters total suspended particles (PTS), inhalable particle $\left(\mathrm{PM}_{10}\right)$ and Ozone $\left(\mathrm{O}_{3}\right)$, as well as the steel industry possibly contributes to this scenario. In comparing the legislations, it was also found that the Brazilian legislation is less restrictive than the others and in need to be updated.
\end{abstract}

\section{Keywords}

Air quality, Volta Redonda, Steel industry.

\section{Como você deve citar?}

ROCHA, Náthaly Lacerda Tonon e; GUIMARÃES, Claudinei de Souza. Estudo da qualidade do ar e a atividade siderúrgica na cidade de Volta Redonda . Cadernos UniFOA, Volta Redonda, n. 33, p. 25-36, abr. 2017. 


\section{INTRODUÇÃO}

O ferro e o aço desempenham um papel importante no desenvolvimento da civilização. A produção mundial de aço aumentou, consideravelmente, desde 2000 e superou a marca de um bilhão de toneladas pela primeira vez, em 2004 (REMUS, 2013). A indústria siderúrgica, sendo de base, tem grande importância estratégica na economia, fornecendo insumos para infraestrutura, suprindo indústrias de construção, naval, ferroviária e automobilística, assim como na geração de emprego (NOLLI et al., 2012). Atualmente há um grande reconhecimento internacional da seriedade e da eficiência da indústria siderúrgica brasileira por sua crescente competitividade, preocupação com o meio ambiente, estrutura de produção e domínio tecnológico. Ainda assim, as usinas produtoras de aço, em função de seus processos, são consideradas grandes atividades poluidoras, e têm como efeitos a poluição de corpos hídricos, emissão de gases causadores do efeito estufa e poluentes atmosféricos que podem causar diversos problemas à saúde humana (SOUZA, 2013; BRITO, 2015).

Cada vez se tornam maiores as preocupações quanto às emissões de poluentes atmosféricos, que impõem a utilização de novos sistemas de controle ambiental (GUIMARÃES, 2016). Essas restrições são estabelecidas através de limites para emissão dos poluentes e, em nível federal, são definidas pelo Conselho Nacional de Meio Ambiente (CONAMA), podendo ser complementadas pelos órgãos estaduais de controle ambiental (OLIVEIRA, 2014).

Sendo assim, o objetivo deste trabalho é realizar uma análise da qualidade do ar da cidade de Volta Redonda, considerando dados disponibilizados pelo Instituto Estadual do Ambiente (INEA), entre os anos de 2010 a 2014, em comparação com a legislação brasileira, europeia e norte-americana, bem como a possível influência das atividades de uma indústria siderúrgica localizada no centro da cidade.

\section{POLUENTES E LEGISLAÇÕES RELACIONADAS À POLUIÇÃO ATMOSFÉRICA}

Pode-se dizer que existe poluição atmosférica quando contém uma ou mais substâncias, definidas na legislação como poluentes, em concentrações suficientes para causar deterioração na qualidade natural do ar, cuja ação possa ser danosa direta ou indiretamente à população e ao meio ambiente (BRAGA et al., 2005; FIGUEIREDO, 2016). Essa degradação é proveniente da interação de diversos fatores, tais como, as emissões das indústrias, automóveis e demais fontes emissoras, as características físico-químicas e as possíveis reações dos poluentes e as condições meteorológicas. (INSTITUTO DE ENERGIA E MEIO AMBIENTE, 2014). Os poluentes que são emitidos em maior quantidade pelas atividades humanas são o monóxido de carbono, os óxidos de enxofre, o material particulado, os hidrocarbonetos e óxidos de nitrogênio. (HINRICHS; KLEINBACH; REIS, 2010).

O CONAMA, órgão legislador brasileiro responsável pelas diretrizes ambientais básicas, estabeleceu padrões nacionais da qualidade do ar através da Resolução nº 03 de 28/06/1990, determinando os limites de concentração dos poluentes, de forma a garantir o bem-estar e a saúde da população, conforme Tabela 01 (BRASIL, 1990). 
Tabela 1 - Padrões Brasileiros de Qualidade do Ar

\begin{tabular}{|lccc|}
\hline Poluente & $\begin{array}{l}\text { Tempo de } \\
\text { amostragem }\end{array}$ & Padrão Primário $\left(\boldsymbol{\mu g} / \mathbf{m}^{3}\right)$ & Padrão Secundário $\left(\mu \mathrm{g} / \mathrm{m}^{3}\right)$ \\
\hline Partículas Totais em Suspensão & 24 horas $(1)$ & 240 & 150 \\
ou Material Particulado (MP) & MGA (2) & 80 & 60 \\
\hline Dióxido de Enxofre $\left(\mathrm{SO}_{2}\right)$ & 24 horas $(1)$ & 365 & 100 \\
\hline Monóxido de Carbono $(\mathrm{CO})$ & MAA & 80 & 40 \\
\hline Ozônio $\left(\mathrm{O}_{3}\right)$ & 1 hora & $40000 / 35 \mathrm{ppm}$ & 40000 \\
\hline Fumaça & 8 horas & $10000 / 9 \mathrm{ppm}$ & 10000 \\
\hline Partículas Inaláveis $\left(\mathrm{MP}_{10}\right)$ & 1 hora & 160 & 160 \\
\hline Dióxido de Nitrogênio $\left(\mathrm{NO}_{2}\right)$ & MAA & 60 & 40 \\
\hline
\end{tabular}

Observações: (1) Não deve ser excedida mais de uma vez ao ano. (2) MGA- Média geométrica anual. (3) MAA - Média aritmética anual. Fonte: (BRASIL, 1990).

A Agência de Proteção Ambiental Americana, assim como o CONAMA, no Brasil, definiu os seguintes padrões de qualidade do ar - vide Tabela 2 (SANTANA et al., 2012).

Tabela 2 - Padrões nacionais de qualidade do ar em vigor nos EUA.

\begin{tabular}{|c|c|c|c|c|}
\hline Poluente & $\begin{array}{l}\text { Primário e/ou } \\
\text { Secundário }\end{array}$ & $\begin{array}{l}\text { Tempo de } \\
\text { amostragem }\end{array}$ & Concentração & Observação \\
\hline \multirow{2}{*}{ CO (2011) } & \multirow{2}{*}{ Primário } & $8 \mathrm{~h}$ & $9 \mathrm{ppm} / 10300 \mu \mathrm{g} / \mathrm{m}^{3}$ & \multirow{2}{*}{$\begin{array}{l}\text { Não deve ser excedido mais que uma } \\
\text { vez ao ano }\end{array}$} \\
\hline & & $1 \mathrm{~h}$ & $35 \mathrm{ppm} / 40057 \mu \mathrm{g} / \mathrm{m}^{3}$ & \\
\hline Chumbo (2008) & $\begin{array}{l}\text { Primário e } \\
\text { Secundário }\end{array}$ & $\begin{array}{l}\text { Média móvel } \\
\text { trimestral }\end{array}$ & $0,15 \mu \mathrm{g} / \mathrm{m}^{3}$ & Não deve ser ultrapassado \\
\hline \multirow[b]{2}{*}{$\mathrm{NO}_{2}(2010)$} & Primário & $1 \mathrm{~h}$ & $100 \mathrm{ppb} / 180 \mu \mathrm{g} / \mathrm{m}^{3}$ & Percentil 98 sobre médias de 3 anos \\
\hline & $\begin{array}{l}\text { Primário e } \\
\text { Secundário }\end{array}$ & Anual & $53 \mathrm{ppb} / 95,4 \mu \mathrm{g} / \mathrm{m}^{3}$ & Média Anual \\
\hline O 3 (Ozônio - 2008) & $\begin{array}{l}\text { Primário e } \\
\text { Secundário }\end{array}$ & $8 \mathrm{~h}$ & $0,075 \mathrm{ppm} / 156 \mu \mathrm{g} / \mathrm{m}^{3}$ & $\begin{array}{l}\text { Quarta maior máxima média diária de } \\
8 \text { horas anual sobre médias de } 3 \text { anos }\end{array}$ \\
\hline \multirow{2}{*}{$\mathrm{MP}_{2,5}(2006)$} & \multirow{2}{*}{$\begin{array}{l}\text { Primário e } \\
\text { Secundário }\end{array}$} & Anual & $15 \mu \mathrm{g} / \mathrm{m}^{3}$ & Média Anual sobre médias de 3 anos \\
\hline & & $24 \mathrm{~h}$ & $35 \mu \mathrm{g} / \mathrm{m}^{3}$ & Percentil 98 sobre médias de 3 anos \\
\hline $\mathrm{MP}_{10}(2006)$ & $\begin{array}{l}\text { Primário e } \\
\text { Secundário }\end{array}$ & $24 \mathrm{~h}$ & $150 \mu \mathrm{g} / \mathrm{m}^{3}$ & $\begin{array}{l}\text { Não deve ser excedido mais que uma } \\
\text { vez por ano sobre médias de } 3 \text { anos }\end{array}$ \\
\hline \multirow{2}{*}{$\mathrm{SO}_{2}(2010)$} & Primário & $1 \mathrm{~h}$ & $75 \mathrm{ppb} / 209 \mu \mathrm{g} / \mathrm{m}^{3}$ & $\begin{array}{l}\text { Percentil } 99 \text { das máximas de } 1 \mathrm{~h} \\
\text { diária(s), média de } 3 \text { anos }\end{array}$ \\
\hline & Secundário & $3 \mathrm{~h}$ & $0,5 \mathrm{ppm} / 1307 \mu \mathrm{g} / \mathrm{m}^{3}$ & $\begin{array}{l}\text { Não deve ser excedido mais de uma } \\
\text { vez por ano }\end{array}$ \\
\hline
\end{tabular}

$\mathrm{MP}_{2,5}$ significa: Material Particulado com dimensão menor que 2,5 micras. Fonte: (SANTANA et al., 2012).

Na União Europeia, os padrões são divididos em "valores-limite" e "valores-alvo" conforme Tabela 03. A diferença se encontra no nível de exigência: os valores-limite são de atendimento obrigatório, a partir da data em que entram em vigor, e os valores-alvo devem ser atingidos na medida do possível até a data estipulada para atendimento, inexistindo penalidades, caso não sejam atingidos no prazo de atendimento (SANTANA et al., 2012). 
Tabela 3 - Padrões Europeus de Qualidade do Ar

\begin{tabular}{|c|c|c|c|c|c|c|c|}
\hline \multirow[b]{2}{*}{ Poluente } & \multicolumn{2}{|c|}{ Valor-Limite } & \multicolumn{2}{|c|}{ Valor-Alvo } & \multirow[b]{2}{*}{$\begin{array}{c}\text { Período de } \\
\text { Amostragem }\end{array}$} & \multirow{2}{*}{$\begin{array}{c}\text { Ultrapassagens } \\
\text { Anuais } \\
\text { Permitidas }\end{array}$} & \multirow[b]{2}{*}{$\begin{array}{l}\text { Margem de } \\
\text { Tolerância }\end{array}$} \\
\hline & Concentração & $\begin{array}{c}\text { Data de } \\
\text { atendimento }\end{array}$ & Concentração & $\begin{array}{c}\text { Data de } \\
\text { atendimento }\end{array}$ & & & \\
\hline \multirow[t]{2}{*}{$\mathrm{MP}_{2,5}$} & $25 \mu \mathrm{g} / \mathrm{m}^{3}$ & $01 / 01 / 2015$ & $25 \mu \mathrm{g} / \mathrm{m}^{3}$ & $01 / 01 / 2010$ & 1 ano & - & $\begin{array}{l}20 \% \text { até } \\
11 / 06 / 2008, \\
\text { a reduzir } \\
\text { gradativamente } \\
\text { até } 0 \% \text { em } \\
1 / 1 / 2015 .\end{array}$ \\
\hline & $20 \mu \mathrm{g} / \mathrm{m}^{3}(\mathrm{a})$ & $01 / 01 / 2020$ & - & - & - & - & - \\
\hline \multirow{2}{*}{$\mathrm{MP}_{10}$} & $50 \mu \mathrm{g} / \mathrm{m}^{3}$ & $01 / 01 / 2005$ & - & - & 24 horas & 35 & $50 \%$ \\
\hline & $40 \mu \mathrm{g} / \mathrm{m}^{3}$ & $01 / 01 / 2005$ & - & - & 1 ano & - & $20 \%$ \\
\hline \multirow{2}{*}{$\mathrm{SO}_{2}$} & $350 \mu \mathrm{g} / \mathrm{m}^{3}$ & $01 / 01 / 2005$ & - & - & 1 hora & 24 & $150 \mu \mathrm{g} / \mathrm{m} 3$ \\
\hline & $125 \mu \mathrm{g} / \mathrm{m}^{3}$ & $01 / 01 / 2005$ & - & - & 24 horas & 3 & - \\
\hline \multirow{2}{*}{$\mathrm{NO}_{2}$} & $200 \mu \mathrm{g} / \mathrm{m}^{3}$ & $01 / 01 / 2010$ & - & - & 1 hora & 18 & $\begin{array}{l}50 \% \text { em } \\
19 / 07 / 1999, \\
\text { a reduzir } \\
\text { gradativamente } \\
\text { até atingir } 0 \% \text { em } \\
1 / 1 / 2010 .\end{array}$ \\
\hline & $40 \mu \mathrm{g} / \mathrm{m}^{3}$ & $01 / 01 / 2010$ & - & - & 1 ano & - & $\begin{array}{l}50 \% \text { em } \\
19 / 07 / 1999, \\
\text { a reduzir } \\
\text { gradativamente } \\
\text { até atingir } 0 \% \text { em } \\
1 / 1 / 2010 .\end{array}$ \\
\hline $\mathrm{CO}$ & $10 \mu \mathrm{g} / \mathrm{m}^{3}$ & $01 / 01 / 2005$ & $120 \mu \mathrm{g} / \mathrm{m}^{3}$ & - & $\begin{array}{l}\text { Média } \\
\text { máxima } \\
\text { diária por } \\
\text { períodos de } \\
8 \text { horas }\end{array}$ & - & $60 \%$ \\
\hline \multirow[t]{2}{*}{$\mathrm{O}_{3}$} & - & - & $120 \mu \mathrm{g} / \mathrm{m}^{3}$ & $01 / 01 / 2010$ & $\begin{array}{l}\text { Média } \\
\text { máxima } \\
\text { diária por } \\
\text { períodos de } \\
8 \text { horas }\end{array}$ & $\begin{array}{l}25 \text { dias em } \\
\text { média por } \\
\text { anos, num } \\
\text { período de } 3 \\
\text { anos }\end{array}$ & - \\
\hline & - & - & $\begin{array}{l}18.000 \mu \mathrm{g} / \\
\mathrm{m}^{3} \cdot \mathrm{h}(\mathrm{b})\end{array}$ & $01 / 01 / 2010$ & $\begin{array}{l}\text { Maio a julho, } \\
\text { num período } \\
\text { de } 5 \text { anos }\end{array}$ & - & - \\
\hline
\end{tabular}

Fonte: (SANTANA et al., 2012).

\section{A SIDERURGIA, SUAS EMISSÕES E SISTEMAS DE CONTROLE}

A indústria siderúrgica tem como objetivo final a produção de aço em suas múltiplas variedades e seu processo pode ser resumido pelas seguintes etapas: extração do minério de ferro; transformação no alto-forno para a obtenção do ferro gusa líquido; refino para a produção do aço na aciaria; lingotamento do aço líquido, a fim de solidificar para as operações seguintes, de laminação e acabamento, onde é feita a conformação do metal na forma de produto (MOURÃO et al., 2007). As siderúrgicas possuem grande potencial para a emissão de poluentes atmosféricos, sendo as principais provenientes da área de metalurgia, que englobam os processos de coqueria, onde ocorre a produção do coque a partir do carvão mineral; de sinterização, onde ocorre a produção do sínter, a partir de finos de minério de ferro, moinha e fundentes; de produção de ferro gusa, no alto forno, e do aço, na aciaria. Em todos esses processos, as principais emissões são de material particulado, óxidos de enxofre e óxidos de nitrogênio (REMUS, 2013; LIMA; ELEBRAS-VEIGA, 2015). 
A qualidade do ar pode ser melhorada através de políticas de controle, sendo o primeiro passo para sua implementação a identificação das fontes específicas que estão contribuindo com a degradação da qualidade do ar, para que se realize o controle adequado das fontes poluidoras. Para as usinas siderúrgicas, suas fontes de emissão são controladas por diversos métodos, tais como, a utilização de combustíveis mais limpos, como os de baixo teor de enxofre ou de cinzas e através de equipamentos de tratamento dos poluentes atmosféricos, como os filtros de manga, coletores gravitacionais, ciclones, lavadores de gases e precipitadores eletrostáticos (CAVALCANTI, 2012; LIANA et al., 2016).

\section{MUNICÍPIO DE VOLTA REDONDA}

Em 1941, a cidade de Volta Redonda/RJ foi escolhida como local para instalação de uma usina siderúrgica, marcando as bases da industrialização brasileira. Com a chegada da indústria, uma mudança na formação socioterritorial da cidade originou-se, e as antigas fazendas de produção de café deram espaço às estruturas da siderúrgica. Com o passar do tempo e com a vinda de milhares de pessoas em busca de trabalho, a população instalou-se ao seu entorno, surgindo também novas edificações e outras pequenas empresas (PORTALVR, 2016).

O município está localizado no trecho inferior do médio vale do rio Paraíba do Sul. Sua área é de $182,483 \mathrm{~km}^{2}$. A altitude da área central é de $380,3 \mathrm{~m}$ acima do nível do mar. A população está estimada em 262.970, de acordo com o IBGE, para o ano de 2015, possuindo uma densidade demográfica (2010) de $1.412,75 \mathrm{hab} / \mathrm{km}^{2}$. A temperatura média é de 21 graus Celsius, com média mínima anual de $16,5^{\circ} \mathrm{Ce}$ média máxima anual de $27,8^{\circ} \mathrm{C}$. 0 índice pluviométrico anual é de $1.337 \mathrm{~mm}$, com uma umidade media anual de $77 \%$. 0 clima predominante é tropical mesotérmico, com inverno frio e seco, verão quente e chuvoso e a direção predominante do vento é no sentido noroeste (IBGE, 2016).

\section{METODOLOGIA}

Os dados de qualidade do ar, referente aos parâmetros Particulados Totais em Suspensão (PTS), Partículas Inaláveis $\left(\mathrm{MP}_{10}\right)$, Dióxido de Enxofre $\left(\mathrm{SO}_{2}\right)$, Dióxido de Nitrogênio $\left(\mathrm{NO}_{2}\right)$, Monóxido de Carbono (CO) e Ozônio $\left(\mathrm{O}_{3}\right)$ foram gerados nas estações de monitoramento existentes na cidade de Volta Redonda e disponibilizados nos relatórios do INEA, para os anos de 2010 a 2014. Seus resultados foram então comparados em tabelas e gráficos com os limites dos poluentes estabelecidos nas legislações brasileira, europeia e norte-americana, no sentido de encontrar possíveis ultrapassagens. Adicionalmente, analisando-se criticamente as legislações citadas, buscou-se identificar diferenças entre os poluentes monitorados e os limites legais estabelecidos nos países considerados.

Por fim, foram observadas a localização das estações de monitoramento e da siderúrgica, a direção do vento e as concentrações dos poluentes, de forma a correlacionar as ultrapassagens dos limites dos poluentes à influência da atividade de siderurgia.

\section{RESULTADOS DO MONITORAMENTO DA QUALIDADE DO AR NA ÁREA DE ESTUDO}

Para a análise e correlação da qualidade do ar da cidade de Volta Redonda com as emissões da siderúrgica existentes, é necessário entender e estudar a meteorologia presente naquela atmosfera e sua preponderância. Nesse sentido, analisando-se a rosa dos ventos, observa-se que a direção predominante ocorre no sentido noroeste. Também, na mesma análise, classificaram-se as estações de monitoramento em relação à dispersão dos poluentes pelo vento como à montante, ou seja, antes da 
interferência industrial, e à jusante, após interferência da siderurgia. Nesse caso, as estações consideradas à montante são as estações Centro, Aeroclube, Volta Grande, Santa Cecília e Jardim Paraíba. As estações consideradas à jusante são as estações Conforto, Belmonte, Siderville, Retiro e Limoeiro.

Figura 1- Rosa dos ventos e mapa de localização das estações de monitoramento

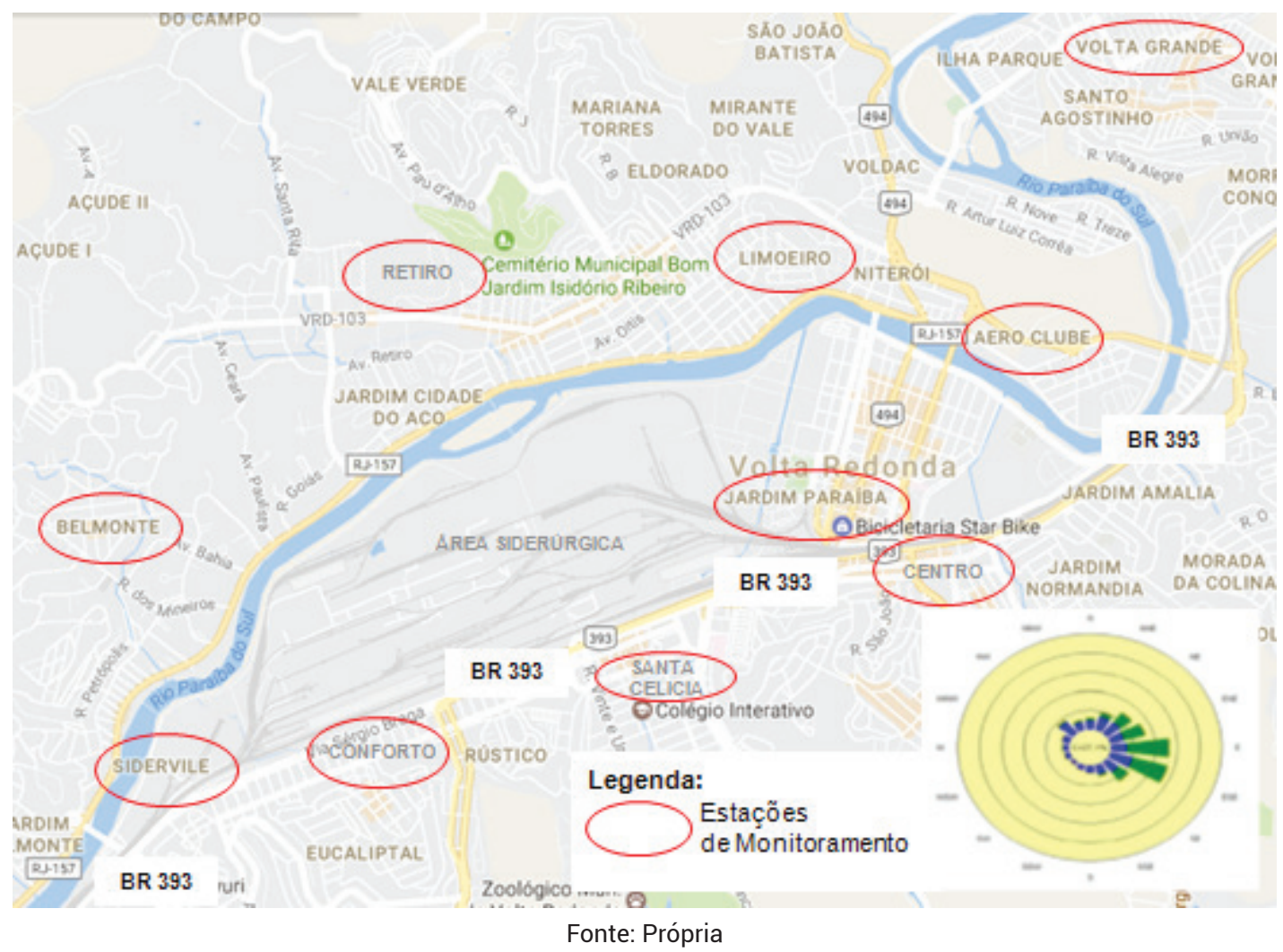

\subsection{Partículas Totais em Suspensão (PTS)}

As comparações entre as máximas concentrações médias diárias de PTS com o padrão estabelecido pela legislação são apresentadas na Figura 2, para exposição de curto período (média de 24h) e, na Figura 3, para exposição de longo período (média geométrica anual). Dentre os anos tabulados, os resultados evidenciam que as concentrações de PTS de exposição de curto período aumentaram ao longo dos anos, observando-se inclusive uma ultrapassagem frente ao limite no ano de 2014, na estação do bairro Conforto. Nota-se ainda que as estações do Centro e do Aeroclube também apresentaram resultados próximos ao limite, demonstrando ser 2014 o pior ano, dentre os avaliados. 
Figura 2 - Gráfico de máximas concentrações médias diárias para Partículas Totais em Suspensão (PTS)

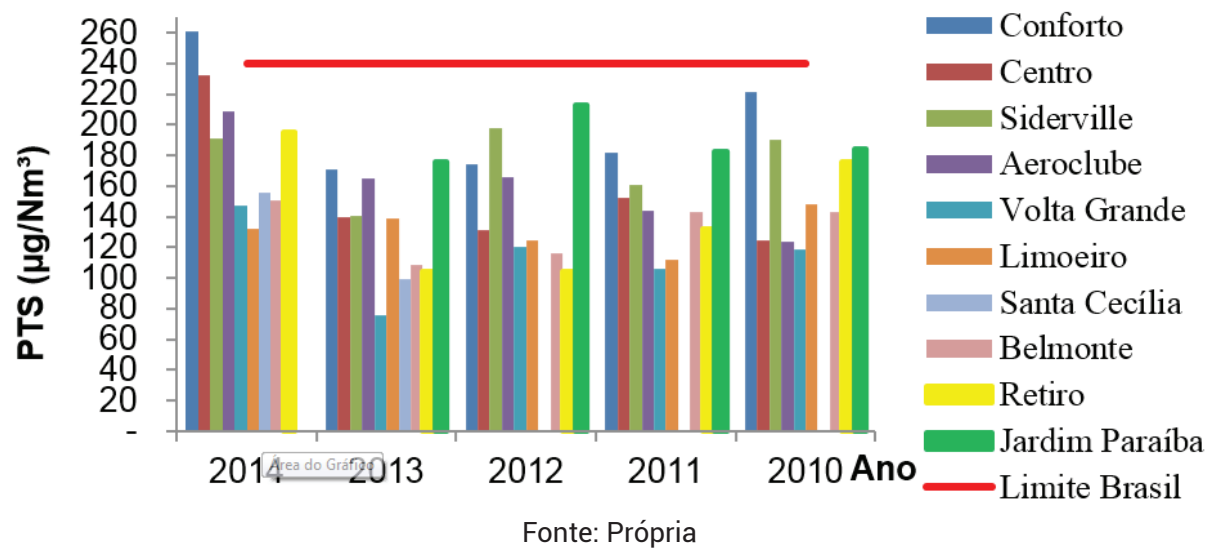

Em relação à exposição de longo período, houve violação do limite no ano de 2014, na estação do Conforto; no ano de 2011, nas estações do Conforto, Siderville e Jardim Paraíba e; no ano de 2010, na estação do Conforto.

Figura 3 - Gráfico de concentrações médias anuais para Partículas Totais em Suspensão (PTS)

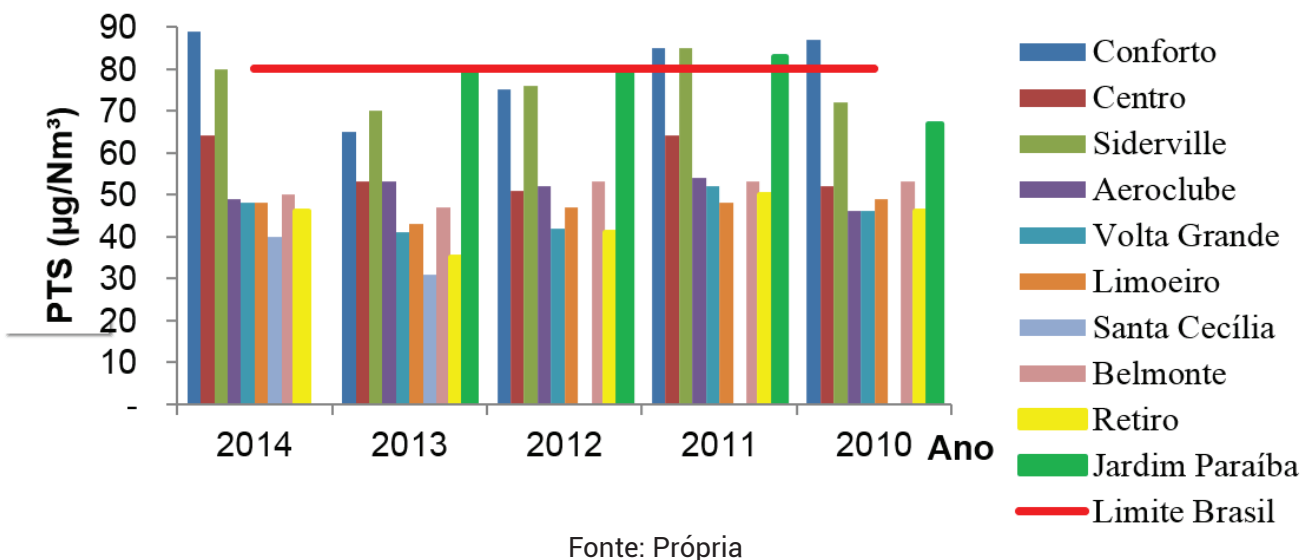

Dentre as estações que estão à jusante da siderurgia, a estação Conforto apresentou ultrapassagens do limite da legislação para diversos anos, enquanto a estação Siderville apresentou unicamente no ano de 2011. Essas estações, por estarem na direção predominante do vento, tem maior possibilidade de sofrerem influência da poluição advinda da siderúrgica. Adicionalmente, observa-se que essas estações encontram-se próximas a uma rodovia de tráfego intenso, a BR 393. A estação Jardim Paraíba, que se encontra à montante, registrou violação do limite em 2010 e resultados muito próximos ao limite, em 2012 e 2013. Por seu posicionamento, nessa estação, torna-se menos provável a influência da siderurgia e sim do tráfego do centro da cidade. Por fim, para o poluente PTS, não foi possível comparar os resultados com a legislação europeia e norte-americana, pois essas legislações não trazem limites para esse parâmetro.

\subsection{Material Particulado Inalável $\left(\mathrm{MP}_{10}\right)$}

As comparações entre as máximas concentrações médias diárias de $\mathrm{MP}_{10}$ com o padrão estabelecido pela legislação são apresentadas na Figura 4, para curto período, (24h) e, na Figura 5, para longo período (média aritmética anual). Nos resultados da Figura 4 observa-se que não houve violação do 
limite durante todos os anos, sendo que a estação Retiro chegou próximo ao padrão no ano de 2014, atingindo $145,00 \mu \mathrm{g} / \mathrm{m}^{3}$. Cabe ainda ressaltar, após análise do gráfico, que o ano de 2014 apresentou o maior valor histórico considerando-se todas as estações avaliadas.

Figura 4 - Gráfico de máximas concentrações médias diárias para Partículas Inaláveis $\left(\mathrm{MP}_{10}\right)$

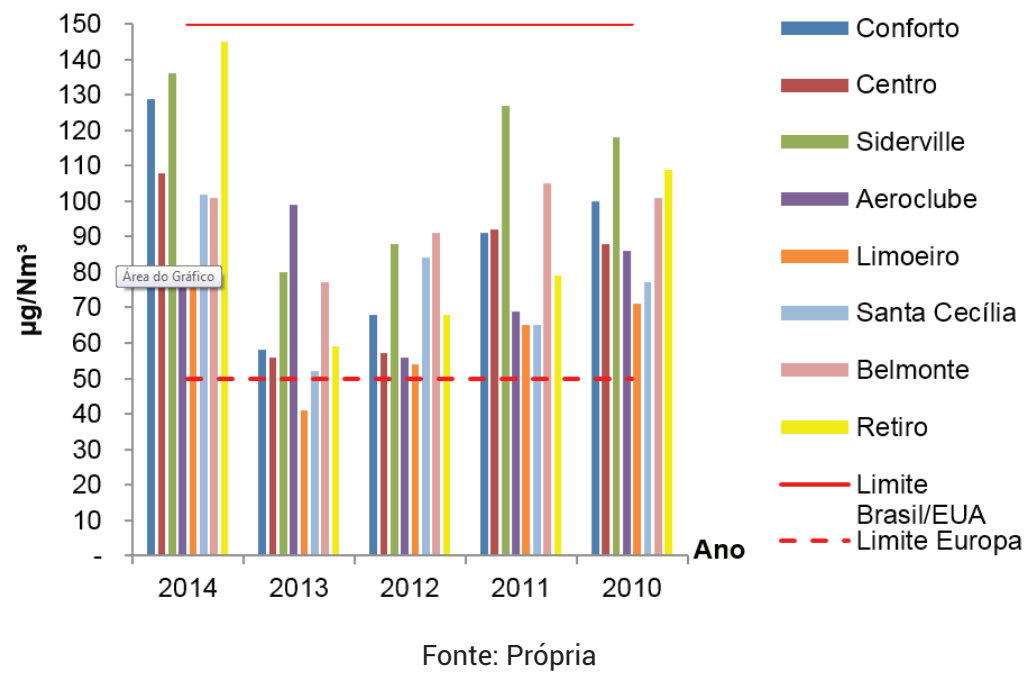

Na figura 5, os valores das concentrações de Partículas Inaláveis indicam somente uma ultrapassagem ao limite estabelecido pela legislação, no ano de 2011 , na estação Siderville.

Figura 5 - Gráfico das concentrações anuais para Partículas Inaláveis $\left(\mathrm{MP}_{10}\right)$

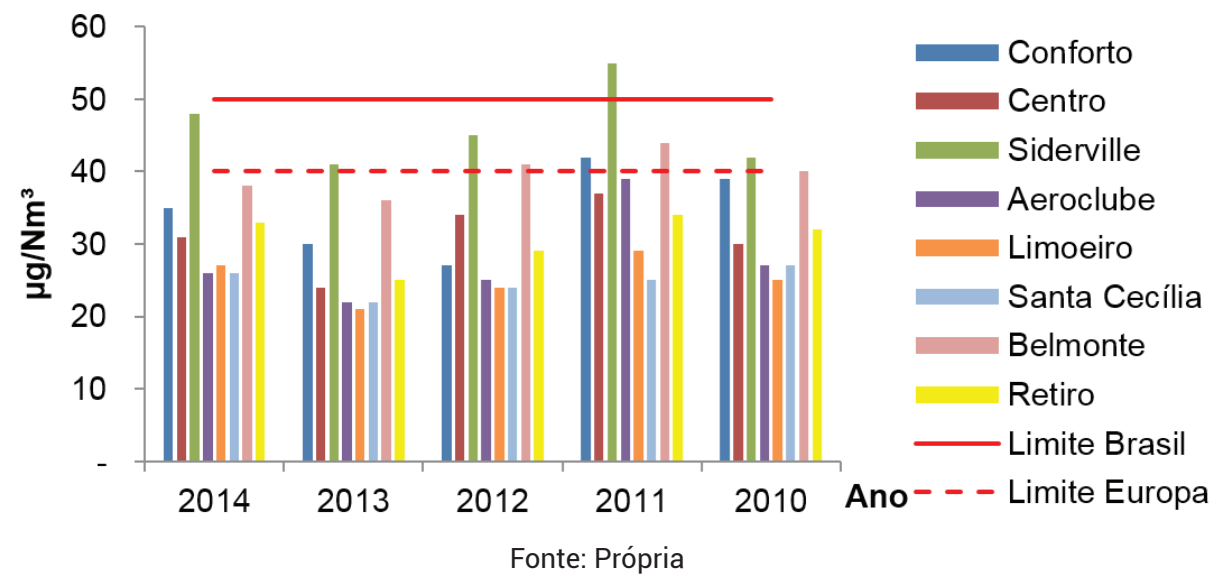

Durante os cinco anos monitorados, somente houve ultrapassagem do limite na estação Siderville, no ano de 2011. Essa estação se encontra à jusante da área siderúrgica e, sendo assim, é possível que parte da contribuição para a violação do padrão tenha ocorrido devido às emissões da siderurgia. Porém, cabe ressaltar que essa estação também se localiza próxima a uma rodovia de fluxo intenso, a BR393. Em relação aos limites estabelecidos pelos outros países, pode-se observar que o limite da Europa é bem mais restritivo que o brasileiro, tanto para curto quanto para longo período. Com relação ao limite norte-americano, os valores são os mesmos da legislação brasileira, porém cabe destacar que, no Brasil, o limite não deve ser excedido mais de uma vez ao ano, enquanto nos Estados Unidos essa 
ultrapassagem anual não é permitida de forma recorrente. Quanto aos resultados das estações, nota-se a violação do limite europeu para curto período de forma generalizada em todos os anos avaliados.

\subsection{Dióxido de Enxofre $\left(\mathrm{SO}_{2}\right)$, Dióxido de Nitrogênio $\left(\mathrm{NO}_{2}\right)$ e Monóxido de Carbono (CO).}

A análise de qualidade do ar para os poluentes $\mathrm{SO}_{2}, \mathrm{NO}_{2}$ e $\mathrm{CO}$ demonstrou uma grande deficiência de monitoramento, pois, além desses parâmetros serem unicamente medidos em apenas três das estações (Belmonte, Santa Cecília e Retiro), apresentaram ausência de dados para diversos anos, evidenciando a falta de controle na rede de monitoramento.

Com os poucos dados existentes, observou-se que não houve registro de ultrapassagem do limite de qualidade do ar de $\mathrm{SO}_{2}$ em nenhuma das estações monitoradas. Comparando com os limites da legislação da Europa, apesar de muito mais restritivos, ainda assim não ocorreram ultrapassagens.

Para o poluente Dióxido de Nitrogênio $\left(\mathrm{NO}_{2}\right)$, também não ocorreram ultrapassagens do limite brasileiro, tanto para exposição a curto, quanto para longo período. Quando se comparou as máximas concentrações horárias com os limites internacionais, a estação Belmonte ultrapassou tanto o limite europeu como o norte-americano, no ano de 2014, bem como também, no ano de 2011, ultrapassou o limite americano e apresentou-se bem próximo ao limite europeu. Tais discrepâncias nos resultados de ultrapassagens, quando comparados os valores às diferentes legislações, demonstram novamente a maior permissividade da legislação brasileira.

O monóxido de carbono não apresentou ultrapassagens para as máximas concentrações horárias e também para as máximas concentrações médias de 8 horas para o padrão brasileiro, o qual é o mesmo que o padrão americano. Em relação ao limite estabelecido pela Europa para a análise das máximas concentrações médias de 8 horas, todas as estações de monitoramento ultrapassaram o limite estabelecido. Novamente, constata-se a maior restrição da legislação europeia frente às demais.

\subsection{Ozônio $\left(\mathrm{O}_{3}\right)$}

As comparações, quanto ao Ozônio, para os anos de 2010 a 2014, estão apresentadas na Figura 6 , destacando-se que esse poluente somente é monitorado nas estações do Belmonte, Santa Cecília e Retiro. Quanto aos resultados dos monitoramentos, ocorreram violações do limite para todas as estações, no ano de 2014, episódio não registrado anteriormente no histórico dos demais anos.

Figura 6 - Gráfico de Máximas Concentrações Horárias para Ozônio.

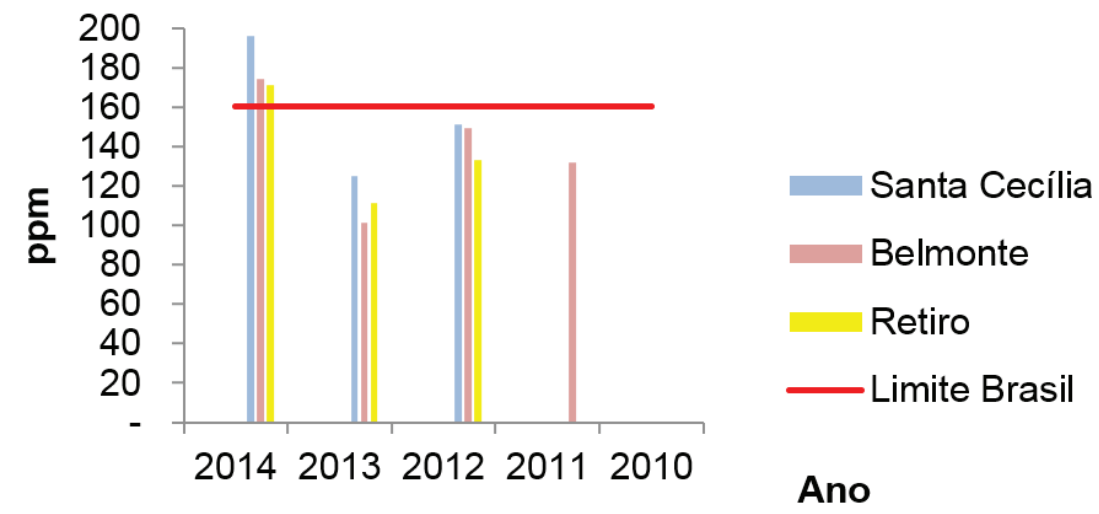

Fonte: Própria 
Por ser um poluente secundário gerado através de reações fotoquímicas, $0 \mathrm{O}_{3}$, não essencialmente, apresenta as maiores concentrações em localidades próximas às maiores fontes emissoras de poluentes primários, tornando sua análise, frente a possível influência da siderurgia, complexa e dependente de modelos matemáticos, os quais não são objetos deste estudo.

\section{CONCLUSÕES E RECOMENDAÇÕES}

Com os resultados da análise de dados, foi possível verificar que as Partículas Totais em Suspensão (PTS), Material Particulado Inalável $\left(\mathrm{MP}_{10}\right)$ e Ozônio $\left(\mathrm{O}_{3}\right)$ ultrapassaram os limites da legislação brasileira, no período de 2010 a 2014. Particularmente, cabe destacar que as estações Conforto e Siderville apresentaram as maiores violações, estando elas localizadas à jusante da atividade siderúrgica, bem como próximas à rodovia BR 393, demonstrando sua possível influência e preocupação com as medidas de controle implantadas. Como sugestões de controle a serem adotadas na siderurgia destacam-se 0 aperfeiçoamento dos equipamentos de tratamento de emissões e as possíveis alterações de combustíveis, enquanto, para o tráfego, destacam-se a fiscalização veicular e adoção de meios de transporte coletivo, de forma a minimizar o fluxo interno na cidade.

Quanto à ausência de dados de monitoramento, cabe atenção dos órgãos responsáveis, para garantir o correto funcionamento das estações, mesmo considerando-se o alto custo de investimento requerido do início ao fim de cada ciclo de monitoramento, mão de obra qualificada e tempo disponível.

Realizando uma comparação dos padrões de qualidade do ar do Brasil, em relação aos da Europa e Estados Unidos, é notória a permissividade dos limites brasileiros, não apenas quanto aos valores estabelecidos, como também quanto à limitação dos parâmetros monitorados, haja vista a existência de obrigatoriedade da análise do Material Particulado Respirável $\left(\mathrm{MP}_{2,5}\right)$ nos demais países. Adicionalmente, cabe registrar que a legislação brasileira não é revisada desde 1990. Esses fatos denotam a urgente necessidade de revisão dos padrões brasileiros.

\section{REFERÊNCIAS}

BRAGA, Benedito; HESPANHOL, Ivanildo; CONEJO, João G. Lotufo; MIERZWA, José Carlos; BARROS, Mario Thadeu L.; SPENCER, Milton; PORTO, Monica; NUCCI, Nelson; JULIANO, Neusa; EIGER, Sérgio. Introdução a Engenharia Ambiental. 2. ed. São Paulo: Pearson Prentice Hall, 2005.

BRASIL, Resolução CONAMA 03, Brasília, Diário Oficial da União, 1990.

BRITO, Haroldo. Impactos da inovação na empresa siderúrgica Arcelormilttal Monlevad: Estudo de Caso. CONCISA - Revista Multidisciplinar da Área de Ciências Sociais Aplicadas, ISSN 2448-1602, Coronel Fabriciano, n. 2, p. 264-287, nov. 2015.

CAVALCANTI, Pedro Porto Silva. Gestão Ambiental na Indústria siderúrgica - Aspectos relacionados às emissões atmosféricas. 2012. 54f. Monografia (Curso de Engenharia Metalúrgica) - Escola Politécnica, Universidade Federal do Rio de Janeiro, Rio de Janeiro, 2012.

ECOLOGUS. Engenharia Consultiva. Planos Municipais de Saneamento Básico e Gestão Integrada de Resíduos Sólidos de Volta Redonda. Documento 2. Plano Municipal de Saneamento Básico. Prefeitura Municipal de Volta Redonda, Secretaria Municipal de Planejamento, 2015. 
FIGUEIREDO, Isabel Peralva. Avaliação de emissões atmosféricos na indústria siderúrgica sob a ótica do controle e monitoramento: 0 caso da CSN. Monografia (Curso de Engenharia Ambiental) - Escola Politécnica, Universidade Federal do Rio de Janeiro, Rio de Janeiro, 2016.

GUIMARÃES, Claudinei de Souza. Controle e Monitoramento de Poluentes Atmosféricos. 1 ed. Rio de Janeiro: Elsevier Editora Ltda, 2016.

HINRICHS, Roger A; KLEINBACH, Merlin; REIS, Lineu Belico. Energia e meio ambiente. 4.ed. São Paulo: Cengage Learning, 2010.

IBGE - Instituto Brasileiro de Geografia e Estatística - Cidades - Rio de Janeiro, Volta Redonda. Disponível em: http://cidades.ibge.gov.br/xtras/perfil.php?codmun=330630 Acesso: Jun/2016.

INEA. Relatório da Qualidade do ar do Estado do Rio de Janeiro 2014. Rio de Janeiro, 2015. 198p.

Relatório da Qualidade do ar do Estado do Rio de Janeiro 2013. Rio de Janeiro, 2014. 188p.

Relatório da Qualidade do ar do Estado do Rio de Janeiro 2012. Rio de Janeiro, 2013. 148p.

Relatório da Qualidade do ar do Estado do Rio de Janeiro 2010 e 2011. Rio de Janeiro, 2012. 141p.

INSTITUTO DE ENERGIA E MEIO AMBIENTE. $1^{\circ}$ Diagnóstico da rede de monitoramento da qualidade do ar do Brasil. 2014.

LIMA, Maira; ELEBRAS-VEIGA, Lilian. Gestão sustentável da Indústria Siderúrgica a partir das premissas da ecologia industrial. 5th International Workshop - Advances in Cleaner Production. Academic Work. Brasil - São Paulo, 2015.

MILANEZ, BRUNO; PORTO, MARCELO. A ferro e fogo: impactos da siderurgia para $\mathrm{o}$ ambiente e a sociedade após a reestruturação dos anos 1990, IV Encontro Nacional da Anppas, 2008.

MOURÃO, Marcelo Breda; YOKOJI, Akira; MALYNOWSKYJ, Antonio; TAKANO, Cesar Alves da Silva Leandro; QUITES, Eduardo Emery Cunha; GENTILE, Erberto Francisco; SILVA, Guilherme F. B. Lenz; BOLOTA, José Roberto; GONÇALVES, Marcelo; FACO, Rubens José. Introdução à siderurgia. São Paulo: Associação Brasileira de Metalurgia e Materiais, 2007.

MURCIA, Liana; ORTIZ, Edison; MARTINS, Jorge; MORAIS, Marcos; ARDILES, Leda; URBINA, Viviana; MARTINS, Leila. Situação atual da qualidade do ar das principias cidades da América Latina, Ciência e Natura, v.38, Ed. Especial - IX Workshop Brasileiro de Micrometeorologia, 2016, p. 523- 531.

NOLLI, THALITA.; ANDRADRE, VAGNER. Oferta de Exportação de Laminados Planos no Brasil Frente à Nova Organização Produtiva do Setor Siderúrgico, Universidade Federal de Juiz de Fora, 2012.

OLIVEIRA, André Albuquerque Bittencourt. Inventário das emissões atmosféricas na indústria siderúrgica. 2014. 85f. Monografia (Curso de Engenharia Metalúrgica) - Escola Politécnica, Universidade Federal do Rio de Janeiro, Rio de Janeiro, 2014.

PORTALVR - Prefeitura Municipal de Volta Redonda - Característica. Disponível em: <http://www. portalvr.com/2012-12-20-11-24-20/caracteristica>. Acesso: 02 jun. 2016. 
REMUS, Rainer; MONSONET, Miguel; ROUDIER, Sarge; SANCHO, Luis. Best Available Techniques (BAT) Reference Document for Iron and Steel Production. Espanha: Europian Comission, 2013.

SANTANA, Eduardo.; CUNHA, Kamyla Borges da.; FERREIRA, André Luis.; ZAMBONI, Ademilson. Padrões de qualidade do ar - Experiência comparada Brasil, EUA e União Europeia. São Paulo: Instituto de Energia e Meio Ambiente, 2012.

SOUZA, RODRIGO. Análise dos Impactos de Emissões Atmosféricas Locais da Indústria Siderúrgica: Um Estudo de Caso no Rio de Janeiro. Instituto Alberto Luiz Coimbra de Pós-Graduação e Pesquisa de Engenharia, Universidade Federal do Rio de Janeiro, 2013. 